\title{
EXTENDED CESÁRO OPERATORS ON BMOA SPACES IN THE UNIT BALL
}

\section{ZHONG-SHAN FANG AND ZE-HUA ZHOU}

Abstract. Let $g$ be a holomorphic map of $B$, where $B$ is the unit ball of $C^{n}$. This paper gives necessary and sufficient conditions for the extended Cesáro operators induced by $g$ to be bounded or compact on BMOA.

Mathematics subject classification (2010): Primary: 47B38; Secondary: 46E15, 32A37..

Keywords and phrases: BMOA space, Extended Cesáro Operators, boundedness; compactness.

\section{REFERENCES}

[1] K. F. Andersen, Cesáro averaging operators on Hardy spaces, Proc. Royal Soc. Edinburgh, 126A (1996), 617-624.

[2] G. BENKE AND D. C. ChAng, A note on weighted Bergman spaces and the Cesáro operator, Nagoya Math. J., 159 (2000), 25-43.

[3] C.C.COWEn AND B.D.MACCLUER, Composition operators on spaces of analytic functions, CRC Press, Boca Raton, FL, 1995.

[4] N. DAniKas And A. Siskakis, The Cesáro operator on bounded analytic functions, Analysis, 13 (1993), 195-199.

[5] P. DURn, Theory of $H^{p}$ space, Academic Press, New York, 1970.

[6] P. Galanopoulos, The Cesáro operator on Dirichlet spaces, Acta Sci. Math., 67 (2001), 441-420.

[7] Z.S. FANG AND Z. H. ZHOU, Extended Cesáro operators on Zygmund spaces in the unit ball, Journal of Computational Analysis and Applications, 11, 3 (2009), 406-413.

[8] D. V. Giang And F. Morricz, The Cesáro operator on Dirichlet is bounded on the Hardy space $H^{1}$, Acta Sci. Math., 61 (1995), 535-544.

[9] Z. J. Hu, Extended Cesáro operators on mixed norm space, Proc. Amer. Math. Soc., 131 (2003), 2171-2179.

[10] Z. J. Hu, Extended Cesáro operators on the Bloch spaces in the unit ball of $C^{n}$, Acta Math. Sci., $23 B$ (2003), 561-566.

[11] S. SteVić And S. LI, Volterra type operators on Zygmund space, Journal of Inequalities and Applications, Volume 2007, Article ID 32124, (2007), 10 pages.

[12] S. Li AND S. STEVIĆ, Integral type operators from mixed-norm spaces to $\alpha$-Bloch spaces, Integral Transform. Spec. Funct., 18, 7 (2007), 485-493.

[13] S. Li AND S. S TEVić, Riemann-Stieltjes operators on Hardy spaces in the unit ball of $C^{n}$, Bull. Belg. Math. Soc. Simon Stevin, 14 (2007), 621-628.

[14] S. Li AND S. STEVić, Riemann-Stieltjes type integral operators on the unit ball in $C^{n}$, Complex Variables Elliptic Functions, 52, 6 (2007), 495-517.

[15] S. Li AND S. STEVIĆ, Compactness of Riemann-Stieltjes operators between $F(p, q, s)$ and $\alpha-B l o c h$ spaces, Publ. Math. Debrecen, 72, 1-2 (2008), 111-128.

[16] S. Li And S. Stević, Riemann-Stieltjes operators between mixed norm spaces, Indian J. Math., 50, 1 (2008), 177-188.

[17] J. Miao, The Cesáro operator is bounded on $H^{p}$ for $0<p<1$, Proc. Amer. Math. Soc., 116 (1992), 1077-1079.

[18] W.Rudin, Function theory in the unit ball of $C^{n}$, Springer-Verlag, New York, 1980. 
[19] A. Siskakis, Composition semigroups and the Cesáro operator on $H^{p}(D)$, J. London Math. Soc., 36 (1987), 153-164.

[20] A. SiskAKIS, Semigroups of composition operators in Bergman spaces, Bull. Austral. th. Soc., 35 (1987), 397-406.

[21] A. Siskakis, The Cesáro operator is bounded on $H^{1}$, Proc. Amer. Math. Soc., 110 (1990), 461-462.

[22] A. SiskAKIS, On the Bergman space norm of the Cesáro operator, Arch. Math., 67 (1996), 312-318.

[23] A. SISKAKIS AND R. ZHAO, A Volterra type operator on spaces of analytic functions, Contemporary Mathematics, 232 (1999), 299-311.

[24] J. H. SHI AND G. B. REN, Boundedness of the Cesáro operator on mixed norm space, Proceeding of the American Mathematical Society, 126 (1998), 3553-3560.

[25] K. Stempak, Cesáro averaging operators, Proc. Royal. Soc. Edinburgh, 124A (1994), 121-126.

[26] J. XIAO, Cesáro-type operators on Hardy, BMOA and Bloch spaces, Arch. Math., 68 (1997), 398-406.

[27] J. XIAO, Riemann-Stieltjes operators on weighted Bloch and Bergman spaces of the unit ball, Journal of the London Mathematical Society. Second Series, 70 (2004), 199-214.

[28] W. S. YANG AND, C. H. OUYANG, Exact location of $\alpha-$ Bloch spaces in $L_{a}^{p}$ and $H^{p}$ of a complex unit ball, Rocky Mountain J. Math, 30 (2000), 1151-1169.

[29] X. J. ZHANG, Extended Cesáro operators on Dirichlet type spaces and Bloch spaces of $C^{n}$, Chin.ANN.of Math., 26A (2005), 139-150. (in Chinese)

[30] Ruhan ZhaO, On a general family of function spaces, Ann. Acad. Sci. Fenn. Math. Dissertationes, 105, 1996, $56 \mathrm{pp}$.

[31] K. H. ZHU, Spaces of Holomorphic functions in the Unit Ball, Springer-Verlag (GTM 226), 2004.

[32] K. H. ZHU, Operator Theory in Function Spaces, Pure and Applied Mathematics 136, Maecel Dekker, Inc., New York-Besel,1990.

[33] Zhuo W. X., OuYANg C. H., Möbius invariant gradient and little $\alpha-$ Bloch functions, Acta Math Scientia, 2002. 